\title{
GMR
}

\section{Correlation between PPARg2 gene Pro12Ala polymorphism and cerebral infarction in an Inner Mongolian Han Chinese population}

\author{
X. Li*, B.L. Zhang*, X.G. Zhang and X.L. Su \\ Clinical Medical Center, Affiliated Hospital, Inner Mongolia Medical College, \\ Huhhot, Inner Mongolia, China \\ *These authors contributed equally to this study. \\ Corresponding author: X.L. Su \\ E-mail: xlsu@hotmail.com
}

Genet. Mol. Res. 15 (2): gmr.15027332

Received September 14, 2015

Accepted November 4, 2015

Published June 21, 2016

DOI http://dx.doi.org/10.4238/gmr.15027332

\begin{abstract}
The variant of PPAR- $g 2$ has been shown to promote the increase of carotid IMT in patients suffering from cerebral infarction and the Pro12Ala polymorphism in the peroxisome proliferatoractivated receptorg2 (PPARg2) gene may be associated with cerebral infarction. However, due to the different genetic background, race, and regional variations of cerebral infarction patient, the results of investigations into this subject differ. The aim of this study was to investigate this polymorphism in relation to cerebral infarction among the Inner Mongolian Han Chinese population. A total of 574 Han Chinese individuals from Inner Mongolian were selected randomly, including 302 patients with cerebral infarction and 272 healthy controls. Polymerase chain reaction-restriction fragment length polymorphism was used to determine genotypes of the PPARg2 Pro12Ala variant and results were confirmed by direct sequencing. Genotype frequencies were found to be 90.7 and $91.9 \%$ for $\mathrm{P} / \mathrm{P}, 8.6$ and $7.7 \%$ for $\mathrm{P} / \mathrm{A}$, and 0.7 and 0.4 for $\mathrm{A} / \mathrm{A}$ in the cerebral infarction and control groups, respectively. No statistically significant differences in genotype distribution were
\end{abstract}


observed between the two groups $(\mathrm{P}>0.05)$. Moreover, PPARg2 Pro12Ala genotype was not significantly associated with altered fasting blood glucose, blood pressure, or serum lipid profiles. After adjustment for gender, body mass index, and smoking habit, logistic regression was used to analyze the relationship between the Pro12Ala polymorphism and cerebral infarction (odds ratio $=0.888,95 \%$ confidence interval $=0.106-7.460, \mathrm{P}>0.05)$, revealing that this variant was not the main pathogenic factor involved. Therefore, the Pro12Ala mutation of PPARg2 may not be associated with cerebral infarction in the Inner Mongolian Han Chinese population.

Key words: Cerebral infarction; PPAR gamma; Mononucleotide; Polymorphism

\section{INTRODUCTION}

Cerebral infarction, also known as cerebral ischemic stroke, is caused by a blood circulatory disorder (Arboix and Alió, 2010). Acute cerebral infarction is a severe neurological disorder in humans, inducing ischemia, hypoxia, necrosis, and lesions in the brain (Hallenbeck, 1996; Zhang et al., 2013). Cerebral infarction is the second most common cause of death worldwide and its incidence is increasing (Lopez et al., 2006). In addition, it can lead to secondary degeneration of the thalamus as well as delay recovery of full functionality (Xing et al., 2012). Hypertension has been considered the most important risk factor in the development of cerebral infarction, and its control is an important preventive measure (Zhang et al., 2006). Some researchers have reported that multiple physiopathological processes could be used to assess cerebral infarction pathogenesis (Tang et al., 2010; Jung et al., 2011; Zhang et al., 2011; Schut et al., 2012), including inflammation, oxidative stress, necrosis, hypercoagulable state, apoptosis, and vascular dysfunction. Therefore, anti-inflammation treatments may help rehabilitation and functional recovery from ischemic brain damage (Liu et al., 2014).

Peroxisome proliferator-activated receptor $\gamma(\operatorname{PPAR} \gamma)$ is a nuclear hormone receptor that exists in four isoforms. The PPARg2 isoform is a ligand-activated transcription factor and a member of the steroid receptor family. It is involved in regulating oxide increases, energy metabolism, cell differentiation, and the inflammatory response, and its role in resistance to atherosclerosis has been affirmed in preliminary work (Spiegelman, 1998). Furthermore, PPARg2 is expressed in adipocytes, vascular smooth muscle cells, macrophages, mesangial cells, and renal epithelial cells (Issemann and Green, 1990). The PPARg2 gene Pro12Ala polymorphism, consisting of a $\mathrm{C}$ to $\mathrm{G}$ base change, leads to the substitution of proline with alanine in codon 12 of exon 2. Proline is able to inhibit the alpha helix formation that alanine encourages, thus amino acid changes lead to altered PPARg2 isoform function (Israel et al., 1992). This Pro12Ala functional variation has been correlated with coronary heart disease (CHD), type 2 diabetes, obesity, and lipid disorders, all of which are important risk factors for cerebrovascular disease. Some authors consider PPARg2 gene variation to be associated with myocardial infarction, type 2 diabetes, and high insulin sensitivity, among other factors, while others have expressed contradictory opinions. However, few studies have reported the relationship between the PPARg2 Pro12Ala polymorphism and cerebral infarction. 
Recently, the relationship between PPARg2 variation and abdominal obesity has been thoroughly demonstrated (Mori et al., 2001; Zietz et al., 2002). Owing to variations in the region characteristic of cerebral infarction patients used in previous investigations, which with genetic background, race, and regional differences, the pertinence of the Pro12Ala polymorphism to cerebral infarction, blood sugar and fat, obesity, and CHD is uncertain. The present study therefore aimed to explore the relationship between the PPARg2 Pro12Ala polymorphism and cerebral infarction, using data obtained from an Inner Mongolian Han Chinese population. Logistic regression analysis was carried out in an effort to further explore the potential association between PPARg2 genotype and allele frequency and gender, age, and clinical indices.

\section{MATERIAL AND METHODS}

\section{Materials and instruments}

Blood Genomic Extraction Kits and 2X Taq Master Mix Kits (Taq DNA polymerase, deoxynucleotide triphosphates, and buffer solution) were purchased from Sigma-Aldrich (MO63103; St. Louis, MO, USA). Polymerase chain reaction (PCR) primers were sourced from Dalian Bao Biological Company (Dalian, China), while restriction enzyme (Bst $\mathrm{UI}$ and buffer solution) was obtained from Beijing New England Biotech Corp. (Beijing, China). The following instruments were used in our protocols: a Microfuge 22R centrifuge (Beckman Coulter, Shanghai, China), a 2720 thermal cycler (Applied Biosystems, Waltham, MA, USA), a DU-800ultraviolet (UV)/visible spectrophotometer (Beckman Coulter), and a DYY electrophoresis apparatus (Beijing Six One Instrument Factory, Beijing, China).

\section{Study subjects}

A total of 302 unrelated hospitalized cerebral infarction patients [171 men and 131 women, with a mean age of $66 \pm 14.0$ years (standard deviation), and no significant age difference between male and female patients $(\mathrm{P}>0.05)$ ] from the Inner Mongolian Han Chinese population were recruited between August and December 2014. All patients were diagnosed as having acute cerebral infarction using cranial computerized tomography or magnetic resonance imaging scans, as per the Fourth National Cerebrovascular Disease Conference. All presented with their first episode of cerebral infarction and received treatment within $48 \mathrm{~h}$ after hospitalization in the Department of Neurology of Affiliated Hospital, Inner Mongolia Medical College. The control group consisted of 272 patients [142 men and 130 women, with a mean age of $60.5 \pm 28.0$ years (standard deviation), and no significant age difference between male and female patients $(\mathrm{P}>0.05)]$ lacking acute cerebral infarction and with no history of stroke, recruited over the same period from the same hospital. Patients were excluded if the cause of cerebral infarction was not one of the following: transient ischemic attacks, cerebral embolism, hematencephalon, subarachnoid hemorrhage, drugs, traumatism, cancer, peripheral vascular disease, blood disease, vascular malformation, or aneurism. Patients with liver/kidney dysfunction, blood or thyroid diseases, severe malnourishment, asthma, and those having used lipid lowering drugs less than one week before the study began were excluded from both groups. All study subjects signed informed consent forms. There were no significant differences in gender and age between the 
two groups, which were comparable. The study was approved by the Research Ethics Committee of Affiliated Hospital, Inner Mongolia Medical College.

\section{DNA extraction}

Firstly, $2 \mathrm{~mL}$ venous blood was collected after subjects had fasted for $8 \mathrm{~h}$, and EDTA was added as an anticoagulant. Blood was then centrifuged at $14,000 \mathrm{rpm}$ for 2 min to separate the serum, before samples were stored at $-86^{\circ} \mathrm{C}$. Secondly, DNA was extracted by a conventional adsorption column method and diluted. The concentration of DNA was tested using a UV/visible spectrophotometer to ensure consistency across samples, and its molecular weight was assessed by agarose gel electrophoresis.

\section{PPARg2Pro12Ala polymorphism test}

PPARg2Pro12Ala polymorphism was determined by PCR-restriction fragment length polymorphism, using previously published methods (Oh et al., 2000; Herrmann et al., 2002). The primer sequences used followed the design of Tavares et al. (2005). The Pro12Ala polymorphism was genotyped by amplification of genomic DNA using the following primers: forward, 5'-CCAATTCAAGCCCAGTCCTTTC-3'; and reverse, 5'-CAGTGAAGGAATCGCTTTCCG-3'. Each PCR consisted of $25 \mu \mathrm{L}$, including $2 \mu \mathrm{L}$ DNA, $0.2 \mu \mathrm{L}$ upstream primer, $0.2 \mu \mathrm{L}$ downstream primers, $12.5 \mu \mathrm{L}$ 2X Taq Master Mix, and 10.1 $\mu \mathrm{L}$ distilled water. The following cycling conditions were used: initial denaturation at $94^{\circ} \mathrm{C}$ for $2 \mathrm{~min}$, followed by 35 cycles of denaturation at $94^{\circ} \mathrm{C}$, annealing at $56^{\circ} \mathrm{C}$, and elongation at $72^{\circ} \mathrm{C}$. Each of these steps lasted $30 \mathrm{~s}$. This was followed by a final extension at $72^{\circ} \mathrm{C}$ for $5 \mathrm{~min}$. Enzyme Bst UI was then used to digest the amplified DNA and the resulting products were resolved by electrophoresis on a $2 \%$ agarose gel stained with ethidium bromide, before being visualized under UV light. Results were documented with a digital camera and stored as computer files using the BioCapt software (Vilbert-Lourmant, Marne LaValle, France).

\section{Genotype analysis}

In order to confirm our results, samples (of $\mathrm{P} / \mathrm{P}, \mathrm{P} / \mathrm{A}$, and $\mathrm{A} / \mathrm{A}$ genotypes) were reamplified and the amplified products were checked and sent to Shanghai Sangon Biotech Co., Ltd. (Shanghai, China) for sequencing (using an ABI Prism 3730 Genetic Analyzer and BigDye Terminator v3.1 reagents, both Applied Biosystems).

\section{Statistical analysis}

All statistical analyses were performed using SPSS version 17.0 (SPSS Inc., Chicago, IL, USA). Continuous data are reported as means \pm standard deviations and the $t$-test was used to determine differences between groups. Using the chi-square test, genotype and allele frequencies were compared among the study groups and Hardy-Weinberg equilibrium was estimated. Logistic regression analysis was employed to determine the relationship between the PPARg2 gene Pro12Ala polymorphism and cerebral infarction. $\mathrm{P}$ values $<0.05$ were considered significant. 


\section{RESULTS}

\section{Analysis of PPARg2 Pro12Ala polymorphism}

The PPARg2 gene Pro12Ala polymorphism was typed by means of a Bst $\mathrm{UI}$ enzyme digest and electrophoresis of the resulting products on a $2 \%$ agarose gel, as shown in Figure 1. The total length of the undigested PCR product was $244 \mathrm{bp}$. Three genotypes were discernible, namely the wildtype homozygous Pro/Pro (P/P), heterozygous Pro/Ala (P/A), and homozygous Ala/Ala (A/A) variants. The $\mathrm{P} / \mathrm{P}$ genotype, in which the restriction enzyme cutting site is absent, was characterized by presence of the full 244-bp band, while the P/A variant includes one DNA strand containing the recognition site, which resulted in digestion products of 244 , 223 , and $21 \mathrm{bp}$. The homozygous A/A genotype was therefore recognizable by the absence of the 244-bp DNA fragment, it having being split into pieces of 223 and $21 \mathrm{bp}$. Randomly selected samples of P/P, P/A, and A/A genotypes were sequenced and, as shown in Figure 2, the results corresponded to those of the enzyme digest.

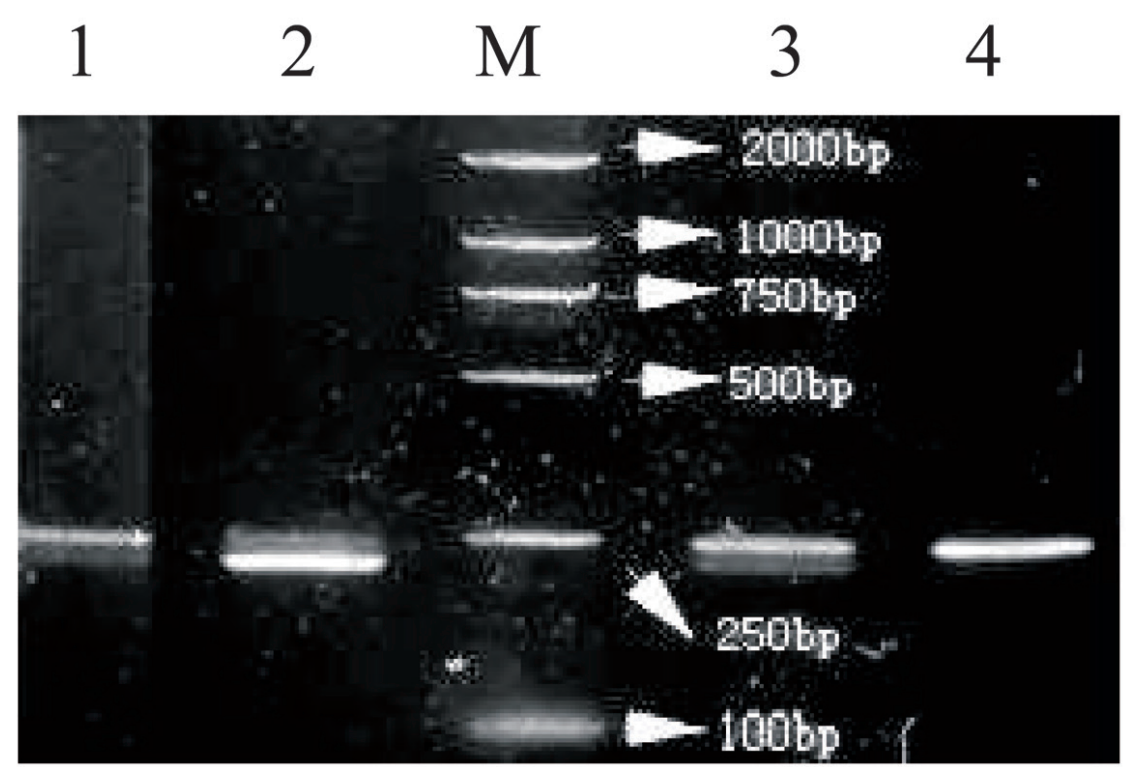

Figure 1. PPARg2 gene Pro12Ala polymorphism was genotyped using enzyme Bst $\mathrm{UI}$ and the digestion products were separated by electrophoresis on a $2 \%$ agarose gel. The lanes were as follows: lane $1=\mathrm{P} / \mathrm{A}$ genotype; lane $2=$ $\mathrm{A} /$ A genotype; lane 3 = P/A genotype; lane $4=\mathrm{P} / \mathrm{P}$ genotype; lane $M=$ molecular weight marker.

\section{Distribution of Pro12Ala allelic and genotypic frequencies in cerebral infarction and control groups}

The characteristics of the study population are presented in Table 1. The Pro12Ala polymorphism was found to be in Hardy-Weinberg equilibrium in both patient and control groups (chi-square, $\mathrm{P}>0.05$ ). $\mathrm{P} / \mathrm{P}, \mathrm{P} / \mathrm{A}$, and $\mathrm{A} / \mathrm{A}$ genotypes were all observed in both groups, 
with the P/P genotype predominating. The frequency of the Ala allele was $5.44 \%$ in our study population. The P/A genotype frequency was 7.7 and $8.6 \%$, while the Ala allele frequency was 4.2 and $5.0 \%$ in the control and case groups, respectively. However, P/A genotype and Ala allele frequencies did not significantly differ between groups, as calculated by combined statistics (chi-square $=0.252, \mathrm{P}=0.616, \mathrm{P}>0.05$ for both groups), the Fisher exact probability method ( $\mathrm{P}>0.05$ for both groups), and allele frequency comparison (chi-square $=0.355, \mathrm{P}=$ $0.551, \mathrm{P}>0.05$ for both groups).
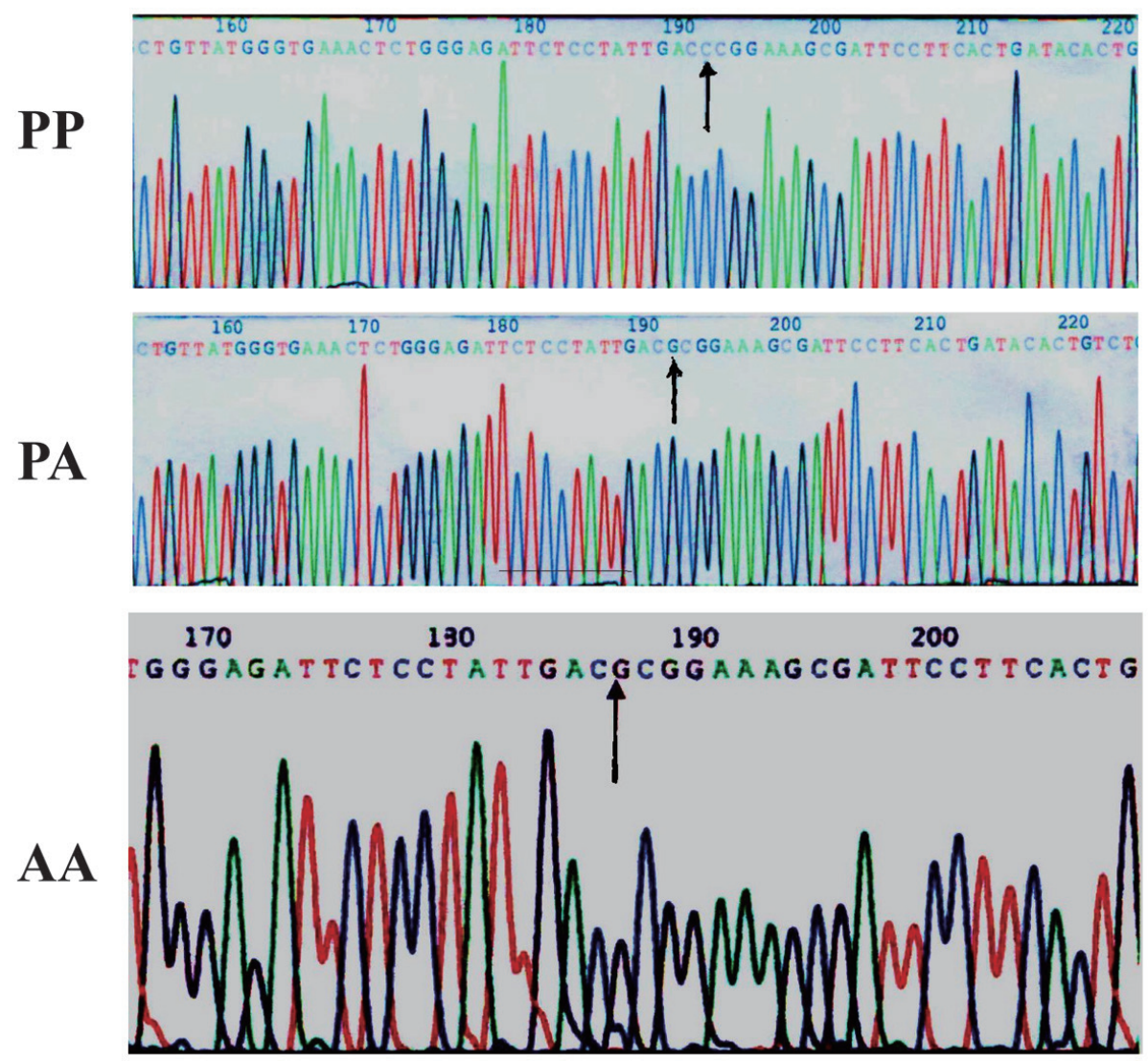

Figure 2. Randomly selected samples of $\mathrm{P} / \mathrm{P}, \mathrm{P} / \mathrm{A}$, and $\mathrm{A} / \mathrm{A}$ genotypes were sequenced.

Table 1. Genotype and allele frequencies of the PPARg2 gene Pro12Ala polymorphism in subjects with or without cerebral infarction (CI).

\begin{tabular}{l|c|c|c|c|c|c}
\hline \multirow{2}{*}{ Group } & $\mathrm{N}$ & \multicolumn{3}{|c|}{ Genotype (\%) } & \multicolumn{3}{c}{ Allele (\%) } \\
\cline { 3 - 7 } & & $\mathrm{P} / \mathrm{P}$ & $\mathrm{P} / \mathrm{A}$ & $\mathrm{A} / \mathrm{A}$ & Pro & Ala \\
\hline CI & 302 & 90.7 & 8.6 & 0.7 & 95.0 & 5.0 \\
\hline Control & 272 & 91.9 & 7.7 & 0.4 & 95.8 & 4.2 \\
\hline & \multicolumn{3}{|c|}{$\mathrm{P}=0.9059$} \\
\hline
\end{tabular}

$\mathrm{P}$ values were derived from chi-square tests. 


\section{Interactions between age, gender, and genotype in cerebral infarction and control groups}

The distribution of Pro12Ala polymorphism genotypes did not significantly differ between study groups, neither when all patients were considered, nor when subgroups based on gender were analyzed. There were no statistically significant differences in genotype or allele frequencies between patients $(\mathrm{P}=0.367)$ and controls $(\mathrm{P}=0.263$; Figure $3 \mathrm{~A}$ and $\mathrm{B})$ of different gender. In the cerebral infarction group, P/P genotype frequencies were 91.8 and $88.7 \%$, while in the control group they were 90.1 and $93.8 \%$ among male and female participants, respectively. Concerning the frequency of $\mathrm{P} / \mathrm{A}+\mathrm{A} / \mathrm{A}$ genotypes, no statistically significant differences were observed in patients ( 8.2 and $11.3 \%$ for male and female individuals, respectively) or controls (9.9 and 6.2\% among male and female participants, respectively). As shown in Figure 3D, no significant difference in genotype frequency was found between the various age categories in the control group ( $\mathrm{P}>0.05$ for all ages). However, as shown in Figure $3 \mathrm{C}$, compared with the $\mathrm{P} / \mathrm{A}+\mathrm{A} / \mathrm{A}$ variants, $\mathrm{P} / \mathrm{P}$ genotype frequency did significantly differ with age among cerebral infarction patients $(\mathrm{P}<0.05)$. In addition, the clinical characteristics of $\mathrm{P} / \mathrm{P}$ genotype carriers within the cerebral infarction group seemed to increase with age (Figure $3 \mathrm{C}$ ).
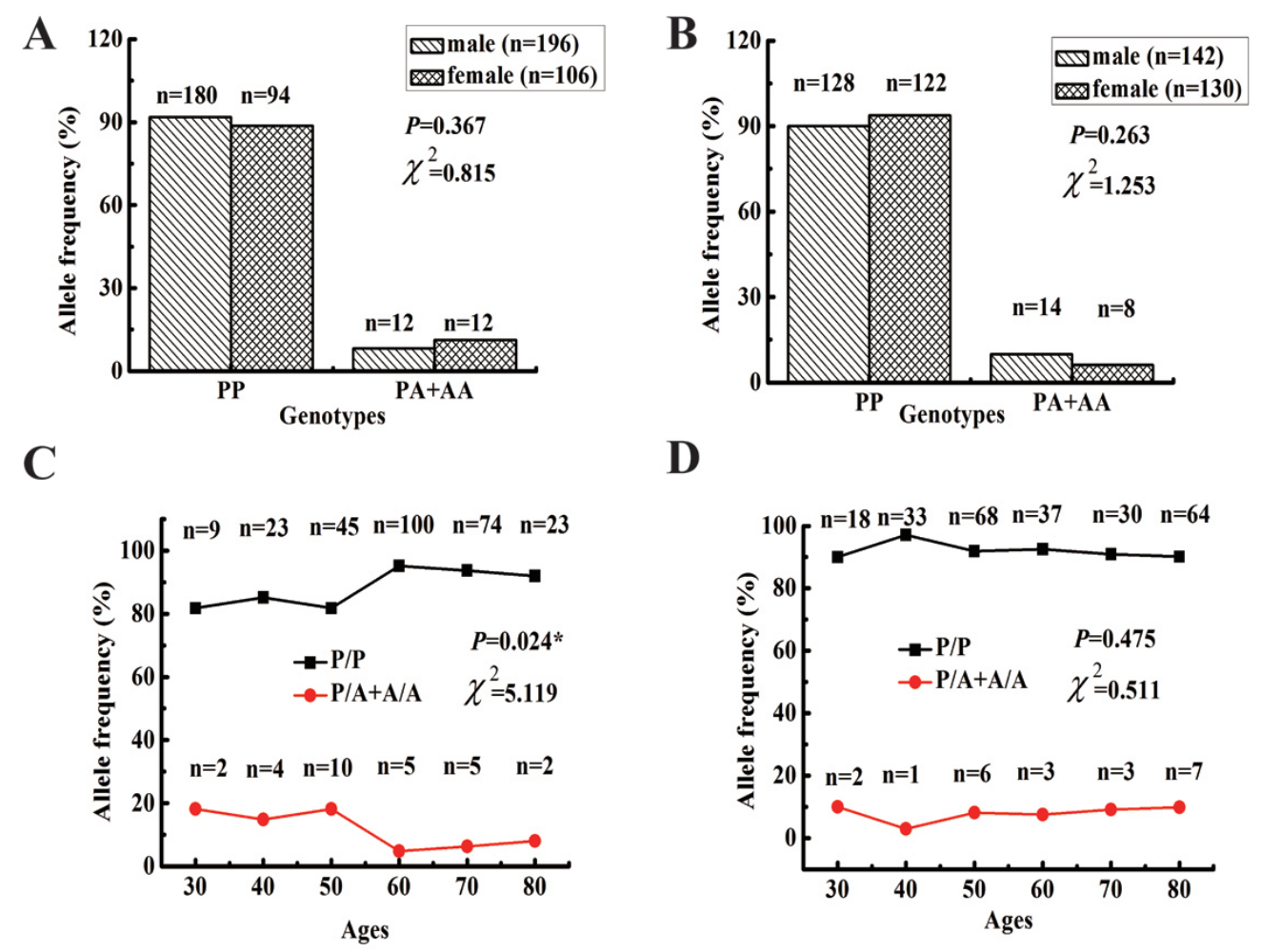

Figure 3. Interactions between age, gender, and PPARg2 Pro12Ala genotype in cerebral infarction and control groups. The frequency of $\mathrm{P} / \mathrm{P}$ and $\mathrm{P} / \mathrm{A}+\mathrm{A} / \mathrm{A}$ genotypes among male and female cerebral infarction patients $(\mathbf{A})$ and controls (B), and in participants of different ages in the cerebral infarction (C) and control (D) groups. P $<0.05$ represents a statistically significant result. 


\section{Clinical characteristics of $\mathrm{P} / \mathrm{P}$ and $\mathrm{P} / \mathrm{A}+\mathrm{A} / \mathrm{A}$ genotype carriers in the cerebral infarction group}

The clinical characteristics associated with $\mathrm{P} / \mathrm{P}$ and $\mathrm{P} / \mathrm{A}+\mathrm{A} / \mathrm{A}$ genotypes are shown in Table 2. Within the cerebral infarction group, compared to those carrying the $\mathrm{P} / \mathrm{P}$ genotype, subjects with $\mathrm{P} / \mathrm{A}+\mathrm{A} / \mathrm{A}$ genotypes demonstrated higher diastolic blood pressure and higher fasting triglyceride (TG) levels. In addition, there was a trend for $\mathrm{P} / \mathrm{P}$ individuals to have lower fasting blood sugar, systolic blood pressure, total cholesterol, and low-density lipoproteincholesterol. These differences, however, did not reach statistical significance $(\mathrm{P}>$ 0.05). Furthermore, body mass index (BMI lower than $24 \mathrm{~kg} / \mathrm{m}^{2}$ ) and TG levels showed no significant differences between genotypes.

Table 2. Clinical characteristics of cerebral infarction patients carrying $\mathrm{P} / \mathrm{P}$ and $\mathrm{P} / \mathrm{A}+\mathrm{A} / \mathrm{A}$ genotypes.

\begin{tabular}{l|c|c|c}
\hline Variable & $\mathrm{P} / \mathrm{P}(\mathrm{N}=274)$ & $\mathrm{P} / \mathrm{A}+\mathrm{A} / \mathrm{A}(\mathrm{N}=28)$ & $\mathrm{P}$ value \\
\hline TC $(\mathrm{mM})$ & $4.75 \pm 1.03$ & $4.79 \pm 1.09$ & 0.860 \\
\hline TGs $(\mathrm{mM})$ & $1.76 \pm 0.99$ & $1.82 \pm 0.70$ & 0.754 \\
\hline HDL-C $(\mathrm{mM})$ & $1.25 \pm 0.44$ & $1.14 \pm 0.30$ & 0.197 \\
\hline LDL-C $(\mathrm{mM})$ & $2.68 \pm 0.78$ & $2.79 \pm 0.82$ & 0.504 \\
\hline BMI $\left(\mathrm{kg} / \mathrm{m}^{2}\right)$ & $23.58 \pm 2.94$ & $23.44 \pm 3.35$ & 0.829 \\
\hline FBS $(\mathrm{mM})$ & $6.20 \pm 2.46$ & $6.30 \pm 2.48$ & 0.834 \\
\hline SBP $(\mathrm{mmHg})$ & $149.05 \pm 18.23$ & $152.54 \pm 18.61$ & 0.337 \\
\hline DBP $(\mathrm{mmHg})$ & $89.16 \pm 12.62$ & $92.93 \pm 11.59$ & 0.131 \\
\hline
\end{tabular}

$\mathrm{TC}=$ total cholesterol; TGs = triglycerides; HDL-C $=$ high-density lipoprotein cholesterol; LDL-C = low-density lipoprotein cholesterol; BMI = body mass index; FBS = fasting blood sugar; SBP = systolic blood pressure; DBP $=$ diastolic blood pressure.

\section{Assessment of cerebral infarction risk factors by logistic regression analysis}

Logistic regression was used to analyze risk factors for cerebral infarction. Seven factors, including age, BMI $\left(>24 \mathrm{~kg} / \mathrm{m}^{2}\right)$, genotype, drinking history, family history of stroke, smoking history, and gender were assessed. Those factors significantly associated with risk of cerebral infarction are shown in Table 3. The following associations remained significant in a logistic regression model after adjustment for the seven factors above: BMI [odds ratio (OR) $=1.467,95 \%$ confidence interval $(95 \% \mathrm{CI})=1.025-2.100]$, smoking history $(\mathrm{OR}=1.645$, $95 \% \mathrm{CI}=1.063-2.544)$, and gender $(\mathrm{OR}=1.620,95 \% \mathrm{CI}=1.159-2.264)$.

Table 3. Cerebral infarction risk factors tested by logistic regression analysis.

\begin{tabular}{l|c|c|c|c}
\hline Variable & Standard error & Regression coefficient & P value & OR (95\%CI) \\
\hline Gender & 0.183 & 0.383 & 0.036 & $1.467(1.025-2.100)$ \\
\hline Smoking history & 0.223 & 0.498 & 0.025 & $1.645(1.063-2.544)$ \\
\hline BMI & 0.171 & 0.483 & 0.005 & $1.620(1.159-2.264)$ \\
\hline
\end{tabular}

$\mathrm{OR}=$ odds ratio; $95 \% \mathrm{CI}=95 \%$ confidence interval; $\mathrm{BMI}=$ body mass index.

\section{DISCUSSION}

The present study constitutes the first assessment of the relationship between the PPARg2 gene Pro12Ala polymorphism and cerebral infarction among the Inner Mongolian 
Han Chinese population. We examined genotype distributions and allele frequencies in cerebral infarction and control groups using PCR amplification, and DNA sequencing. The association between cerebral infarction and this PPARg2 polymorphism was also analyzed based on clinical characteristics and risk factors. However, no significant association was found between Pro12Ala variants and cerebral infarction.

Cerebral infarction represents a serious danger to human health. Hypertension, diabetes mellitus, and dyslipidemia have been demonstrated by others to be related to cerebral infarction, and are recognized as traditional risk factors (Park et al., 2014). Genetics and molecular biology studies have revealed the existence of genetic predisposition to cerebral infarction, and have identified various polymorphisms associated with this condition (Domingues-Montanari et al., 2008; Xu et al., 2008). Atherosclerosis, the inflammatory response, and impaired vascular endothelial function play an important role in the development of cerebral infarction (Pucci et al., 2011; Soskić et al., 2011). The fact that PPAR $\gamma$ mediates effects on atherosclerosis, insulin resistance, inflammation, and lipoprotein metabolism may be relevant to this disease (Gallardo-Soler et al., 2008; Dubuisson et al., 2011).

The type II nuclear receptor PPAR $\gamma$ is an important regulator known to be involved in glucose metabolism, insulin resistance, atherosclerosis, lipid metabolism, and adipokinesis (Spiegelman, 1998; Cock et al., 2004). It has been reported that PPARg2Pro12Ala polymorphism allele frequencies differ by country, region, and ethnic group. The minor allele frequency of this polymorphism is $12 \%$ among Caucasians, $10 \%$ in the United States, $3 \%$ in African-Americans, $8 \%$ among Samoans, and $4 \%$ in the Japanese population. Concerning the country in which this study was carried out, the $\mathrm{P} / \mathrm{P}$ genotype predominates and the Ala allele frequency stands at approximately $2-4 \%$, similar to that in the Japanese population (Xiang and Zhu, 2006; Zhao et al., 2010). This is also the most prevalent genotype in European and American populations, in which the Ala allele is found at a frequency of around $10 \%$, a substantially higher figure than that observed in Asian groups. Studies of different nationalities and regions in China have shown that the Ala allele frequency among Koreans in the Yanbian area and Ningxia Hui Hunan, and in Changsha, Shanghai, and other regions are approximately the same as in the general population, i.e., lower than in Caucasian groups and other Europeans. It can be seen therefore that the distribution of genotypes and alleles of the PPARg2 Pro12Ala polymorphism shows ethnic and regional differences (Dong et al., 2004; Jin et al., 2007; Tianet al., 2010).

Considering the reported beneficial effect on the kidneys of thiazolidinedione stimulation of PPARg2, a mutation in this gene would be expected to confer an adverse effect and lead to reduced activity. The Pro12Ala polymorphism was originally examined for an association with obesity, cardiovascular disease traits, and diabetes, with varying results in different populations and subgroups (Lohmueller et al., 2003; Tönjes et al., 2006). To date, few studies have focused on cerebral infarction within the Inner Mongolian Han Chinese population. Prior studies have revealed that the PPARg2 Pro12Ala polymorphism is associated with development of atherosclerosis, but is not linked to the hereditary component of cerebral infarction among the Chinese population of Changsha (Hang et al., 2007). Data from these (Hang et al., 2007) previous investigations revealed an Ala allele frequency of 5.2\% in cerebral infarction patients, higher than the $5.0 \%$ recorded in our case group.

Studies of associations between Pro12Ala variants and cerebral infarction have yielded conflicting results. A Finnish study (Pihlajamäki et al., 2000) reported that carriers of the A/A genotype exhibit higher TG levels compared to P/P individuals. However, in the 
current investigation, BMI $\left(>24 \mathrm{~kg} / \mathrm{m}^{2}\right)$ and TG levels were not significantly different between $\mathrm{P} / \mathrm{P}, \mathrm{P} / \mathrm{A}$, and $\mathrm{A} / \mathrm{A}$ genotype groups. Moreover, in the adjusted risk factor analysis, BMI (OR $=1.467,95 \% \mathrm{CI}=1.025-2.100)$, smoking history $(\mathrm{OR}=1.645,95 \% \mathrm{CI}=1.063-2.544)$, and gender $(\mathrm{OR}=1.620,95 \% \mathrm{CI}=1.159-2.264)$ were identified as the principal factors in cerebral infarction development. Our results demonstrate that the PPARg2Pro12Ala polymorphism is not associated with cerebral infarction.

The chief objective of this analysis was to investigate the correlation between the PPARg2 gene Pro12Ala polymorphism and cerebral infarction by evaluating genotype and allele frequencies, risk factors, and clinical characteristics of cerebral infarction patients. Overall, our results revealed that allele frequencies and clinical parameters did not significantly differ between cerebral infarction patients and the control group. This suggests that the Pro12Ala mutation of the PPARg2 gene may not be associated with cerebral infarction among the Inner Mongolian Han Chinese population.

\section{Conflicts of interest}

The authors declare no conflict of interest.

\section{ACKNOWLEDGMENTS}

We are grateful to all those who participated in this study. Research supported by a grant from the National Natural Science Foundation of China (\#81260058).

\section{REFERENCES}

Arboix A and Alió J (2010). Cardioembolic stroke: clinical features, specific cardiac disorders and prognosis. Curr. Cardiol. Rev. 6: 150-161. http://dx.doi.org/10.2174/157340310791658730

Cock TA, Houten SM and Auwerx J (2004). Peroxisome proliferator-activated receptor-gamma: too much of a good thing causes harm. EMBO Rep. 5: 142-147. http://dx.doi.org/10.1038/sj.embor.7400082

Domingues-Montanari S, Mendioroz M, del Rio-Espinola A, Fernández-Cadenas I, et al. (2008). Genetics of stroke: a review of recent advances. Expert Rev. Mol. Diagn. 8: 495-513. http://dx.doi.org/10.1586/14737159.8.4.495

Dong Y, Li G, Luo TH, Wu G, et al. (2004). Study of Pro12Ala polymorphism in peroxisome proliferator-activated receptor-g2 gene with type 2 diabetes in Shanghai Han population. Arademic J. Shanghai Second Med. Univ. 24: 345-347.

Dubuisson O, Dhurandhar EJ, Krishnapuram R, Kirk-Ballard H, et al. (2011). PPARgamma-independent increase in glucose uptake and adiponectin abundance in fat cells. Endocrinology 152: 3648-3660. http://dx.doi.org/10.1210/ en.2011-0225

Gallardo-Soler A, Gómez-Nieto C, Campo ML, Marathe C, et al. (2008). Arginase I induction by modified lipoproteins in macrophages: a peroxisome proliferator-activated receptor- $\gamma / \delta$-mediated effect that links lipid metabolism and immunity. Mol. Endocrinol. 22: 1394-1402. http://dx.doi.org/10.1210/me.2007-0525

Hallenbeck JM (1996). Significance of the inflammatory response in brain ischemia. Acta Neurochir. Suppl. (Wien) 66: 27-31.

Hang L, Gu WP, Li W, Wang NN, et al. (2007). Relationship between PPARr2 gene Pro12Ala polymorphism and cerebral infarction. Pract. Prev. Med. 14: 289-291.

Herrmann SM, Ringel J, Wang JG, Staessen JA, et al.; Berlin Diabetes Mellitus (BeDiaM) Study (2002). Peroxisome proliferator-activated receptor-gamma2 polymorphism Pro12Ala is associated with nephropathy in type 2 diabetes: The Berlin Diabetes Mellitus (BeDiaM) Study. Diabetes 51:2653-2657. http://dx.doi.org/10.2337/diabetes.51.8.2653

Israel DI, Nove J, Kerns KM, Moutsatsos IK, et al. (1992). Expression and characterization of bone morphogenetic protein-2 in Chinese hamster ovary cells. Growth Factors 7: 139-150. http://dx.doi.org/10.3109/08977199209046403

Issemann I and Green S (1990). Activation of a member of the steroid hormone receptor superfamily by peroxisome 
proliferators. Nature 347: 645-650. http://dx.doi.org/10.1038/347645a0

Jin MH, Jin YH, Yang KJ, Liu Y, et al. (2007). Association of PPAR-g2 gene Pro12Ala polymorphism with type2 diabetes mellitus in Korean-Chinese nationality and Han-Chinese in Yanbian area. J. Med. Sci. Yanbian Univ. 30: 4-8.

Jung JY, Lee HS, Kang DG, Kim NS, et al. (2011). 1H-NMR-based metabolomics study of cerebral infarction. Stroke 42: 1282-1288. http://dx.doi.org/10.1161/STROKEAHA.110.598789

Liu J, Xing Y, Gao Y and Zhou C (2014). Changes in serum interleukin-33 levels in patients with acute cerebral infarction. J. Clin. Neurosci. 21: 298-300. http://dx.doi.org/10.1016/j.jocn.2013.04.036

Lohmueller KE, Pearce CL, Pike M, Lander ES, et al. (2003). Meta-analysis of genetic association studies supports a contribution of common variants to susceptibility to common disease. Nat. Genet. 33: 177-182. http://dx.doi. org/10.1038/ng1071

Lopez AD, Mathers CD, Ezzati M, Jamison DT, et al. (2006). Global and regional burden of disease and risk factors, 2001: systematic analysis of population health data. Lancet 367: 1747-1757. http://dx.doi.org/10.1016/S0140$\underline{6736(06) 68770-9}$

Mori H, Ikegami H, Kawaguchi Y, Seino S, et al. (2001). The Pro12 $\rightarrow$ Ala substitution in PPAR- $\gamma$ is associated with resistance to development of diabetes in the general population: possible involvement in impairment of insulin secretion in individuals with type 2 diabetes. Diabetes 50: 891-894. http://dx.doi.org/10.2337/diabetes.50.4.891

Oh EY, Min KM, Chung JH, Min YK, et al. (2000). Significance of Pro12Ala mutation in peroxisome proliferatoractivated receptor-gamma2 in Korean diabetic and obese subjects. J. Clin. Endocrinol. Metab. 85: 1801-1804.

Park JH, Lee HS, Kim JH, Lee JH, et al. (2014). Reverse dipper and high night-time heart rate in acute stage of cerebral infarction are associated with increased mortality. J. Stroke Cerebrovasc. Dis. 23: 1171-1176. http://dx.doi. org/10.1016/j.jstrokecerebrovasdis.2013.10.010

Pihlajamäki J, Miettinen R, Valve R, Karjalainen L, et al. (2000). The Pro12A1a substitution in the peroxisome proliferator activated receptor gamma 2 is associated with an insulin-sensitive phenotype in families with familial combined hyperlipidemia and in nondiabetic elderly subjects with dyslipidemia. Atherosclerosis 151: 567-574. http://dx.doi. org/10.1016/S0021-9150(99)00433-5

Pucci A, Formato L, Muscio M, Brscic E, et al. (2011). PPAR $\gamma$ in coronary atherosclerosis: in vivo expression pattern and correlations with hyperlipidemic status and statin treatment. Atherosclerosis 218: 479-485. http://dx.doi. org/10.1016/j.atherosclerosis.2011.06.009

Schut ES, Lucas MJ, Brouwer MC, Vergouwen MD, et al. (2012). Cerebral infarction in adults with bacterial meningitis. Neurocrit. Care 16: 421-427. http://dx.doi.org/10.1007/s12028-011-9634-4

Soskić SS, Dobutović BD, Sudar EM, Obradović MM, et al. (2011). Peroxisome proliferator-activated receptors and atherosclerosis. Angiology 62: 523-534. http://dx.doi.org/10.1177/0003319711401012

Spiegelman BM (1998). PPAR-gamma: adipogenic regulator and thiazolidinedione receptor. Diabetes 47: 507-514. http:// dx.doi.org/10.2337/diabetes.47.4.507

Tang NY, Liu CH, Hsieh CT and Hsieh CL (2010). The anti-inflammatory effect of paeoniflorin on cerebral infarction induced by ischemia-reperfusion injury in Sprague-Dawley rats. Am. J. Chin. Med. 38: 51-64. http://dx.doi. org/10.1142/S0192415X10007786

Tavares V, Hirata RD, Rodrigues AC, Monte O, et al. (2005). Association between Pro12Ala polymorphism of the PPAR-g2 gene and insulin sensitivity in Brazilian patients with type-2 diabetes mellitus. Diabetes Obes. Metab. 7: 605-611. http://dx.doi.org/10.1111/j.1463-1326.2004.00453.x

Tian ZG, Qiang D and Xie XM (2010). Correlation between polymorphism in PPAR- $\gamma$ gene and type 2 diabetes mellitus in Hui and Han people in Ningxia. Guangdong Med. J. 31: 2372-2374.

Tönjes A, Scholz M, Loeffler M and Stumvoll M (2006). Association of Pro12Ala polymorphism in peroxisome proliferator-activated receptor gamma with Pre-diabetic phenotypes: meta-analysis of 57 studies on nondiabetic individuals. Diabetes Care 29: 2489-2497. http://dx.doi.org/10.2337/dc06-0513

Xiang J and Zhu DL (2006). Research progress in the gene polymorphism of PARg2 and Pro12Ala. Chin. J. Pract. Int. Med 26: 1979-1981.

Xing S, Zhang Y, Li J, Zhang J, et al. (2012). Beclin 1 knockdown inhibits autophagic activation and prevents the secondary neurodegenerative damage in the ipsilateral thalamus following focal cerebral infarction. Autophagy 8 : 63-76. http://dx.doi.org/10.4161/auto.8.1.18217

Xu X, Li J, Sheng W and Liu L (2008). Meta-analysis of genetic studies from journals published in China of ischemic stroke in the Han Chinese population. Cerebrovasc. Dis. 26: 48-62. http://dx.doi.org/10.1159/000135653

Zhang B, Wu T, Song C, Chen M, et al. (2013). Association of CD40--1C/T polymorphism with cerebral infarction susceptibility and its effect on sCD40L in Chinese population. Int. Immunopharmacol. 16: 461-465. http://dx.doi. org/10.1016/j.intimp.2013.04.028 
Zhang H, Thijs L and Staessen JA (2006). Blood pressure lowering for primary and secondary prevention of stroke. Hypertension 48: 187-195. http://dx.doi.org/10.1161/01.HYP.0000231939.40959.60

Zhang XH, Lei H, Liu AJ, Zou YX, et al. (2011). Increased oxidative stress is responsible for severer cerebral infarction in stroke-prone spontaneously hypertensive rats. CNS Neurosci. Ther. 17: 590-598. http://dx.doi.org/10.1111/j.17555949.2011.00271.x

Zhao LR, Su XL, Chen LG and Wang LP (2010). The mechanism of PPAR $\gamma$ and PGC-1 and the progression of genes mononucleotide polymorphism. Acta Acad Med NeiMongol 32: 426-429.

Zietz B, Barth N, Spiegel D, Schmitz G, et al. (2002). Pro12Ala polymorphism in the peroxisome proliferator-activated receptor-g2 (PPARgamma2) is associated with higher levels of total cholesterol and LDL-cholesterol in male Caucasian type 2 diabetes patients. Exp. Clin. Endocrinol. Diabetes 110: 60-66. http://dx.doi.org/10.1055/s-2002-23487 